\title{
$\alpha 4$-integrin receptor desaturation and disease activity return after natalizumab cessation
}

\section{OPEN}

Tobias Derfuss, MD*

John M. Kovarik, PhD*

Ludwig Kappos, MD

Marina Savelieva, $\mathrm{PhD}$

Richa Chhabra,

MS (Pharm)

Avinash Thakur,

MS (Pharm)

Ying Zhang, PhD

Heinz Wiendl, MD

Davorka Tomic, DVM

Correspondence to

Dr. Derfuss:

Tobias.Derfuss@usb.ch

Supplemental data at Neurology.org/nn

\section{ABSTRACT}

Objective: To describe the time course of $\alpha 4$-integrin receptor desaturation and disease activity return in patients with relapsing-remitting MS who discontinued natalizumab and to investigate baseline and on-study predictors for the recurrence of disease activity.

Methods: In the course of TOFINGO, a 32-week, patient- and rater-blinded multicenter, parallelgroup study, we performed MRI, counted relapses, and measured $\alpha 4$-integrin receptor occupancy (RO) at baseline and 8, 12, 16, 20, and 24 weeks. The relationship between $\mathrm{RO}$ and total number of new T1 gadolinium-enhancing ( $\mathrm{Gd}+$ ) lesions was modeled using Poisson linear regression.

Results: Patients ( $N=142)$ were randomized (1:1:1) to 8-, 12-, or 16-week washout (WO) groups. At randomization, the median RO in the 8-, 12-, and 16-week WO groups was 94.5\%, 92.4\%, and $90.9 \%$, which declined to $79.8 \%, 30.7 \%$, and $8.7 \%$ after 8,12 , and 16 weeks of WO, respectively. The percentage of patients with new T1 Gd+ lesions increased with longer WO period before commencing fingolimod: $2.1 \%$ (8 weeks), 9.1\% (12 weeks), and 50.0\% (16 weeks). Overall, 71\% of patients with first relapse between weeks 6 and 18 had RO values below the time-matched population median. Higher T2 lesion volume (LV) at baseline predicted a higher number of new T1 Gd+ lesions.

Conclusions: A faster decline in natalizumab RO, longer WO period, and higher T2 LV at baseline were associated with an increased risk for return of inflammatory disease activity. These results provide a mechanistic rationale and, together with the main outcomes of the TOFINGO study, support initiation of fingolimod within 8 weeks of natalizumab discontinuation.

ClinicalTrials.gov identifier: NCT01499667. Neurol Neuroimmunol Neuroinflamm 2017;4:e388; doi: 10.1212/NXI.0000000000000388

\section{GLOSSARY}

FACS = fluorescence-assisted cell sorter; $\mathbf{G d}+=$ gadolinium enhancing; $\mathbf{L N I}=$ last natalizumab infusion; $\mathbf{L V}=$ lesion volume; RO = receptor occupancy; RRMS = relapsing-remitting MS; WO = washout.

Patients with relapsing-remitting MS (RRMS) often discontinue natalizumab treatment, most frequently due to the risk of developing progressive multifocal leukoencephalopathy. ${ }^{1}$ Natalizumab discontinuation leads to recurrence of clinical and radiologic disease activity within 4 months of discontinuation. ${ }^{2}$ Natalizumab primarily acts via blocking the $\alpha 4-$ integrin receptor and preventing potentially autoaggressive immune cell transition through the blood-brain barrier. ${ }^{2}$ Hence, $\alpha 4$-integrin receptor desaturation should be a direct measure of its therapeutic activity. No systematic studies have reported the relationship between $\alpha 4$-integrin receptor occupancy $(\mathrm{RO})$ and recurrence of disease activity following natalizumab discontinuation.

\footnotetext{
*These authors contributed equally to the manuscript.

From the Neurological Clinic and Policlinic (T.D.), Departments of Medicine and Biomedicine, University Hospital Basel; Novartis Pharma AG (J.M.K., M.S., D.T.), Basel; Neurological Clinic and Policlinic (L.K.), Departments of Medicine, Clinical Research, Biomedicine and Biomedical Engineering, University Hospital Basel, Switzerland; Novartis Pharmaceuticals Corporation (Y.Z.), East Hanover, NJ; and Department of Neurology (H.W.), University of Münster, Germany; Novartis Healthcare Pvt. Ltd. (R.C.. A.T.), Hyderabad, India.

Funding information and disclosures are provided at the end of the article. Go to Neurology.org/nn for full disclosure forms. The Article Processing Charge was funded by Novartis.

This is an open access article distributed under the terms of the Creative Commons Attribution-NonCommercial-NoDerivatives License 4.0 (CC BY-NC-ND), which permits downloading and sharing the work provided it is properly cited. The work cannot be changed in any way or used commercially without permission from the journal.
} 


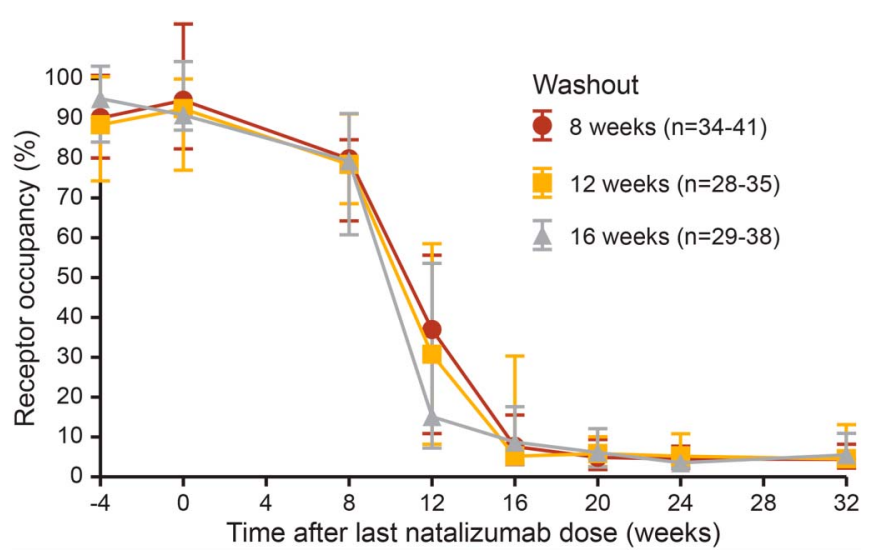

Receptor desaturation after the last natalizumab dose. Median $\alpha 4$-integrin receptor occupancy by the WO group at screening ( -4 weeks), randomization (week 0$)$, and during drug WO from weeks 8 to 32 . Bars represent the IQR. A total of 137 patients (96.5\%) provided at least 1 evaluable receptor occupancy measurement. IQR $=$ interquartile range; $\mathrm{WO}=$ washout.
In daily practice, fingolimod $0.5 \mathrm{mg}$ is frequently considered a suitable option for treatment of patients with RRMS after natalizumab discontinuation, but the optimal washout (WO) period remains unknown. ${ }^{3}$ TOFINGO, a randomized double-blind study, addressed the relationship between the duration of natalizumab WO before fingolimod initiation and recurrence of disease activity. ${ }^{4}$ The results of TOFINGO suggested that better control of disease activity is achieved if fingolimod is initiated within 8-12 weeks after natalizumab discontinuation, compared with 16 weeks. $^{4}$ In the course of TOFINGO, blood samples were collected to determine $\alpha 4$-integrin $\mathrm{RO}$. We investigated the time course of $\alpha 4$-integrin receptor desaturation and its temporal relation to MRI and clinical disease activity. Other possible baseline and on-study predictors for the recurrence of disease activity were also assessed. The analysis was aimed to provide a mechanistic rationale for the timing of switch from natalizumab to fingolimod in patients with RRMS.

METHODS Study design and patients. TOFINGO (ClinicalTrials.gov identifier: NCT01499667), a 32-week, patient- and rater-blinded, randomized, multicenter, parallelgroup study, included 142 patients with RRMS who received their last natalizumab infusion (LNI; $300 \mathrm{mg}$ IV) within \pm 7 days of randomization. Details of the study have been published previously. ${ }^{4}$ Briefly, patients with RRMS aged $18-65$ years who had received natalizumab treatment for $\geq 6$ months immediately before screening were randomized 1:1:1 to one of the following 3 natalizumab WO groups before fingolimod therapy was initiated: 8-week WO (no treatment for 8 weeks since LNI followed by 24 weeks of treatment with oral fingolimod $0.5 \mathrm{mg}$ ); 12-week WO (no treatment for 8 weeks since LNI and placebo for 4 weeks followed by 20 weeks of treatment with fingolimod); or 16-week WO (no treatment for 8 weeks since LNI and placebo for 8 weeks followed by 16 weeks of treatment with fingolimod). All patients in the study population provided written informed consent. TOFINGO involved 44 study centers and was conducted in accordance with the ethical principles of the Declaration of Helsinki.

Study assessments. Natalizumab serum concentration and $\alpha 4$-integrin $R O$ assessment. Patient visits were scheduled at screening, randomization, and weeks $8,12,16,20,24$, and 32 . At each visit, the serum concentration of natalizumab was determined using a validated ELISA method (lower quantification limit, $0.1 \mu \mathrm{g} / \mathrm{mL}$ ). Venous blood samples were collected at all visits to determine $\alpha 4$-integrin RO (\%) using a fluorescenceassisted cell sorter (FACS) analysis. Cells were stained with matched isotype control antibodies to determine the specificity of $\alpha 4$ integrin and natalizumab staining. The signal obtained with matched isotype controls was used to set the threshold for CD49d-specific $\alpha 4$-integrin staining and/or antinatalizumab staining with anti-IgG4 reagent. Natalizumab (final concentration, $10 \mu \mathrm{g}$ ) was spiked in $150 \mu \mathrm{L}$ whole blood samples. The samples were incubated with detection antibodies, CD49dspecific $\alpha 4$-integrin staining, CD3 staining, and/or antinatalizumab staining with anti-IgG4 reagent, for 15 minutes in the dark at $23^{\circ} \mathrm{C}$. BD FACS lysing solution $(2 \mathrm{~mL})$ was added to the sample and incubated for 15 minutes in the dark at $23^{\circ} \mathrm{C}$. The samples were then pelleted by centrifugation and washed twice with $2 \mathrm{~mL}$ of FACS Flow Sheath Fluid. One hundred thousand nucleated events were then analyzed on FACS Calibur, using FSC/CD3 staining for T-lymphocyte gating and determination of $\alpha 4$-integrin and natalizumab-positive CD3 cells and median fluorescence intensity of $\alpha 4$-integrin and natalizumab staining.

Assessment of disease recurrence. MRI assessments (T1 gadolinium-enhancing $[\mathrm{Gd}+]$ lesion counts; new T2 lesions) were conducted at baseline and at weeks 8,12,16,20, and 24. All relapses during the study (both confirmed and not confirmed) were counted.

The association between $\mathrm{RO}$ and freedom from $\mathrm{T} 1 \mathrm{Gd}+$ lesions was explored using median-effect analysis. ${ }^{5}$ The relationship between RO, patient-specific covariates, and total number of T1 Gd+ lesions was modeled using Poisson linear regression (e-Methods at Neurology.org/nn).

RESULTS Patient disposition and baseline characteristics. Overall, 142 patients were randomized (8-week WO: $\mathrm{n}=50$; 12-week WO: $\mathrm{n}=42$; and 16-week WO: $\mathrm{n}=50$ ) and analyzed according to the WO group assigned at randomization. As reported previously, baseline demographic and MS characteristics were well balanced across the WO groups. ${ }^{4}$ Of the 142 patients, $137(96.5 \%)$ provided $\geq 1$ evaluable RO measurement. The percentage of patients providing evaluable $\mathrm{RO}$ values at each visit averaged $72 \%$ (range, 58\%-83\%). The median serum concentration of natalizumab at the end of WO for the 8-, 12-, and 16-week WO groups was $0 \mu \mathrm{g} / \mathrm{mL}$, with a range of $0-1.07,0-0.383$, and $0-0.308 \mu \mathrm{g} / \mathrm{mL}$, 
A

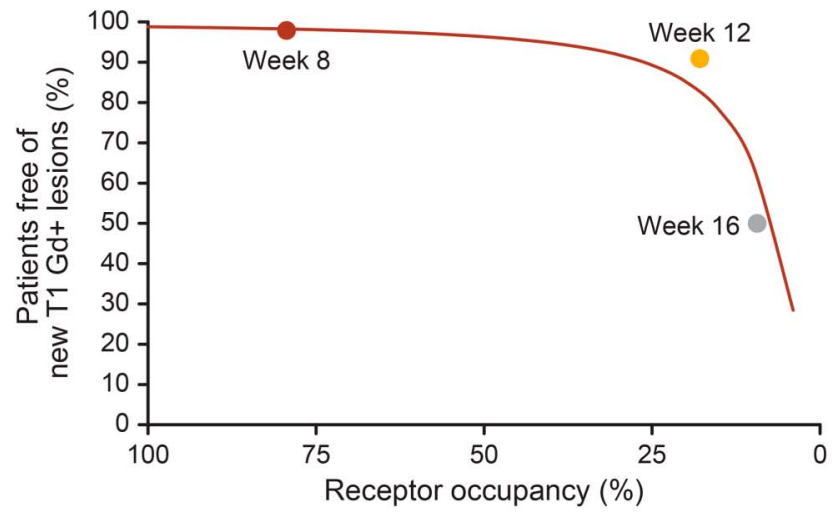

B

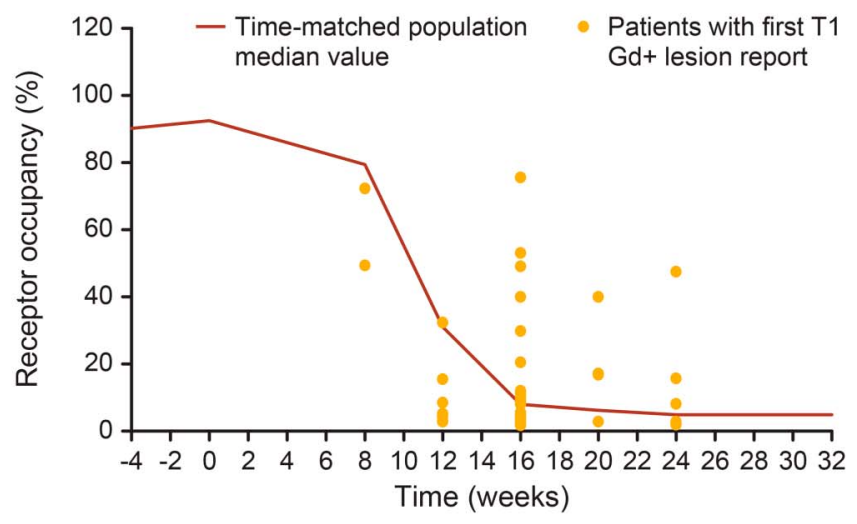

(A) Median-effect modeling of receptor occupancy and freedom from T1 Gd+ lesions. Scatter plot of the percentage of patients free from $\mathrm{T} 1 \mathrm{Gd}+$ lesions vs median $\alpha 4$-integrin receptor occupancy for the 8-, 12-, and 16-week WO groups. Only patients not yet on fingolimod were included in the analysis. The curve represents the fit of the median-effect model to the data. (B) Median receptor occupancy and first reporting of T1 Gd+ lesions. Scatter plot showing the $\alpha 4$-integrin receptor occupancy at the visit when first $\mathrm{T} 1 \mathrm{Gd}$ + lesions were reported in the context of the population median receptor desaturation curve. $\mathrm{Gd}+$ = gadolinium enhancing; $\mathrm{WO}=$ washout.

respectively (table e-1), indicating that in most patients, the drug was eliminated from blood in the first 2 months after LNI.
$90.9 \%$ in the 8-, 12-, and 16-week WO groups, respectively. Overall, the median $\mathrm{RO}$ declined to $79.8 \%, 30.7 \%$, and $8.7 \%$ at weeks 8,12 , and 16 , respectively (figure 1). MRI scans were available for 121 patients. As the length of the WO period before fingolimod initiation increased, the percentage of patients free from $\mathrm{T} 1 \mathrm{Gd}+$ lesions decreased, although the relationship did not reach statistical significance (median-effect analysis, $\mathrm{r}^{2}=0.891, p=0.214$; figure 2A). Up to week 8, the median $\mathrm{RO}$ was relatively high (79.4\%), and the incidence of new T1 Gd+ lesions was $2.1 \%(\mathrm{n}=2)$. Both these patients with new T1 Gd+ lesions had ROs below the population median. By week 12 , the median RO had declined to $17.9 \%$, and the percentage of patients with new $\mathrm{T} 1 \mathrm{Gd}+$ lesions was $9.1 \%$. At week 16 , the median $\mathrm{RO}$ was $9.35 \%$, and the percentage of patients with new $\mathrm{T} 1 \mathrm{Gd}+$ lesions was the highest $(50.0 \%$; figure $2 \mathrm{~B})$. Similar results were observed with RO and the first reporting of new/ enlarging T2 lesions (data not shown). Overall, 31 patients had at least 1 relapse, 26 of whom had RO data available. Of these, 17 had the first relapse between weeks 6 and 18 . The majority $(n=12 ; 71 \%)$ of these 17 patients had RO values below the time-matched population median (figure e-1).

Model-based prediction of T1 Gd+ lesions and new/ enlarging T2 lesions. High T2 lesion volume (T2 LV) at baseline was associated with a higher number of $\mathrm{T} 1$ $\mathrm{Gd}+$ lesions after LNI. As shown in figure 3, patients with baseline $\mathrm{T} 2 \mathrm{LV}<75$ th percentile experienced fewer new $\mathrm{T} 1 \mathrm{Gd}+$ lesions than did those with a baseline $\mathrm{T} 2 \mathrm{LV}>75$ th percentile. This was observed in all WO groups, most noticeable in the 16-week WO group (e-Results).

DISCUSSION Patients with RRMS frequently switch to fingolimod after natalizumab discontinuation to

Figure 3

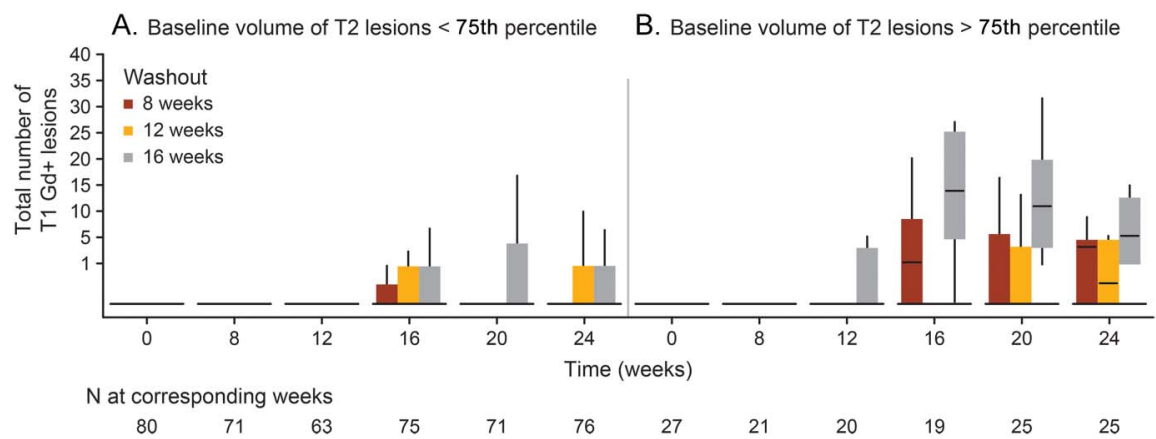

Total number of T1 Gd+ lesions when the baseline volume of T2 lesions was less than (A) and greater than (B) the 75th quartile. Bottom of box is Q1 and the top of the box is Q3; upper whiskers are $1.5 \times$ IQR of the hinge; lower whiskers are $1.5 \times$ IQR of the hinge. Gd $+=$ gadolinium enhancing; IQR = interquartile range. 
maintain adequate disease control. ${ }^{6,7}$ Several observational studies and the randomized rater- and patientblinded TOFINGO study have suggested that a natalizumab WO period of $>12$ weeks is associated with higher risk of disease reactivation, ${ }^{4,6}$ and that a WO period of $<12$ weeks is associated with lower MRI activity without being associated with increased risks. ${ }^{4,6,8}$ Our study also suggests that in $~ 80 \%$ of patients, disease recurrence (new T1 Gd+ lesions) is low up to week 12 during the WO period before fingolimod initiation. Significant disease return is observed between weeks 12 and 16 of the WO period at an $\mathrm{RO}$ of $<20 \%$ (figure $2 \mathrm{~A}$ ). This might indicate that an RO lower than $90 \%$ is still sufficient to suppress disease activity. However, recent small studies have shown that some patients may relapse or have recurrence of MRI activity within 8 weeks of LNI, indicating possibilities of an early switch to fingolimod. ${ }^{9,10}$ While a long WO period between LNI and fingolimod initiation may increase the risk of disease recurrence, early initiation of fingolimod may result in additive effects on protective immune functions.

Despite a small sample size, the TOFINGO study showed distinct numerical trends in pharmacodynamics, imaging, and clinical outcomes, which can help determine the risk of disease recurrence after natalizumab discontinuation in individual patients.

Our results showed that while natalizumab is cleared from the serum within 8-12 weeks after discontinuation, it still occupies $\alpha 4$-integrin receptors, thus contributing to disease activity control. In view of the association of declining $\mathrm{RO}$ with recurring disease activity, $\mathrm{RO}$ may emerge as a more plausible measure for an individualized choice of the optimal WO period. Ideally, decisions regarding the optimal WO period would also take the individual risk profile into account. In addition to prenatalizumab relapse rate and MRI activity, which have previously been identified as risk factors, our study suggests that a high baseline T2 LV defines a patient population with an increased risk of recurrence after discontinuation.

\section{AUTHOR CONTRIBUTIONS}

The study was designed by the sponsor, Novartis Pharma AG, in collaboration with the steering committee. Data were collected by the investigators and analyzed by the sponsor. Novartis contributed to the interpretation of the study. All authors had full access to the data and had final responsibility for the contents and decision to submit for publication. T. Derfuss and J.M. Kovarik: design and conceptualization of the study, analysis and interpretation of the data, and drafting and revising the manuscript. L. Kappos: analysis and interpretation of the data and revising the manuscript. M. Savelieva: design and conceptualization of the study, statistical analysis and interpretation of the data, and revising the manuscript. $\mathrm{H}$. Wiendl: design and conceptualization of the study, analysis and interpretation of the data, and drafting and revising the manuscript. Y. Zhang: design and conceptualization of the study, statistical analysis and interpretation of the data, and revising the manuscript. D. Tomic: design and conceptualization of the study, analysis and interpretation of the data, and drafting and revising the manuscript. R. Chhabra; drafting and revising the manuscript. A. Thakur: drafting and revising the manuscript.

\section{ACKNOWLEDGMENT}

The authors thank the patients from whom data were taken for analysis. They thank Rebecca Gottschalk (Novartis Pharmaceuticals Corporation, East Hanover, NJ) for coordination of the study. All authors edited the manuscript for intellectual content, provided guidance during manuscript development, and approved the final version submitted for publication.

\section{STUDY FUNDING}

The study was sponsored by Novartis Pharma AG.

\section{DISCLOSURE}

T. Derfuss serves on scientific advisory boards for Novartis Pharmaceuticals, Merck Serono, Biogen, Sanofi Genzyme, GeNeuro, Octapharma, MedDay, Mitsubishi Pharma, Roche, and Bayer Schering Pharma; has received funding for travel and/or speaker honoraria from Biogen, Sanofi Genzyme, Novartis Pharmaceuticals, Merck Serono, Roche, and Bayer Schering Pharma; is on the editorial board for PLoS One; receives research support from Biogen, Novartis Pharma, the European Union, the Swiss National Foundation, and the Swiss MS Society; is a member of steering committee for Mitsubishi Pharma and GeNeuro; and his spouse is an employee of and owns stock options in Novartis Pharma. J.M. Kovarik is on the editorial board for Journal of Clinical Pharmacology and is employed by and holds stock in Novartis. L. Kappos' institution (University Hospital Basel) has received in the last 3 years and used exclusively for research support: steering committee, advisory board, and consultancy fees (Actelion, Addex, Bayer HealthCare, Biogen Idec, Biotica, Genzyme, Lilly, Merck, Mitsubishi, Novartis, Ono Pharma, Pfizer, Receptos, Sanofi, Santhera, Siemens, Teva, UCB, and Xenoport); speaker fees (Bayer HealthCare, Biogen Idec, Merck, Novartis, Sanofi, and Teva); support for educational activities (Bayer HealthCare, Biogen, CSL Behring, Genzyme, Merck, Novartis, Sanofi, and Teva); license fees for Neurostatus products; and grants (Bayer HealthCare, Biogen Idec, European Union, Merck, Novartis, Roche Research Foundation, Swiss MS Society, and Swiss National Research Foundation). L. Kappos is on the editorial board for Multiple Sclerosis Journal, Multiple Sclerosis and Related Disorders, and Journal of Neurology. M. Sevelieva is employed by Novartis Pharma. R. Chhabra is employed by Novartis Healthcare. A. Thakur is employed by Novartis Healthcare. Y. Zhang is employed by Novartis Pharma. H. Wiendl served on the scientific advisory board for Bayer Healthcare, Biogen Idec, Sanofi Genzyme, Merck Serono, Novartis, Roche, and Teva; is on the editorial board for PLoS One, Neurotherapeutics, and Recent Patents on Inflammation and Allergy Drug Discovery; has received compensation for serving as a consultant or speaker for, or has received research support from Bayer Schering Pharma, Biogen Idec/Elan Corporation, CSL Behring, EMD Serono, Fresenius Medical Care, OmniaMed, GlaxoSmithKline, GW Pharmaceuticals, Bayer Vital, Sanofi Genzyme, Roche, Merck Serono, Novartis, Novo Nordisk, Sanofi Aventis, Teva Pharmaceutical Industries, German Ministry for Education and Research, European Union, Interdisciplinary Centre of Clinical Research, and PML Consortium; and Else Kroner Fresenius Foundation, Fresenius Foundation, Hertie Foundation, and RE Children's Foundation. D. Tomic holds a patent on fingolimod's activity on T1 hypointense lesions; is employed by Novartis; and holds stock in Novartis. Go to Neurology.org/nn for full disclosure forms.

Received May 15, 2017. Accepted in final form June 27, 2017.

\section{REFERENCES}

1. Bloomgren G, Richman S, Hotermans C, et al. Risk of natalizumab-associated progressive multifocal leukoencephalopathy. N Engl J Med 2012;366:1870-1880.

2. Rasenack M, Derfuss T. Disease activity return after natalizumab cessation in multiple sclerosis. Expert Rev Neurother 2016;16:587-594. 
3. Klotz L, Grutzke B, Eveslage M, et al. Assessment of immune functions and MRI disease activity in relapsing-remitting multiple sclerosis patients switching from natalizumab to fingolimod (ToFingo-Successor). BMC Neurol 2015;15:96.

4. Kappos L, Radue EW, Comi G, et al. Switching from natalizumab to fingolimod: a randomized, placebocontrolled study in RRMS. Neurology 2015;85:29-39.

5. Chou TC, Talalay P. Quantitative analysis of dose-effect relationships: the combined effects of multiple drugs or enzyme inhibitors. Adv Enzyme Regul 1984;22:27-55.

6. Jokubaitis VG, Li V, Kalincik T, et al. Fingolimod after natalizumab and the risk of short-term relapse. Neurology 2014;82:1204-1211.

7. Naegelin Y, Rasenack M, Blatti C, et al. Switching from natalizumab to fingolimod: recurrence of disease activity is closely related to duration of wash out and alpha- 4 integrin desaturation-a prospective study in RRMS. Mult Scler J 2015;21(11 suppl):556-557.

8. Cohen M, Maillart E, Tourbah A, et al. Switching from natalizumab to fingolimod in multiple sclerosis: a French prospective study. JAMA Neurol 2014;71:436-441.

9. Fox RJ, Cree BA, De Seze J, et al. MS disease activity in RESTORE: a randomized 24-week natalizumab treatment interruption study. Neurology 2014;82:1491-1498.

10. Naegelin Y, Rasenack M, Sanderson N, et al. An observational study evaluating disease control, safety, and immunological changes in patients with relapsing remitting multiple sclerosis switching from previous treatment with natalizumab to fingolimod (SWITCH-UHBS). Mult Scler J 2013;19(11 Suppl):460. 


\title{
Neurology \\ Neuroimmunology \& Neuroinflammation
}

\author{
$\alpha 4$-integrin receptor desaturation and disease activity return after natalizumab \\ cessation \\ Tobias Derfuss, John M. Kovarik, Ludwig Kappos, et al. \\ Neurol Neuroimmunol Neuroinflamm 2017;4; \\ DOI 10.1212/NXI.0000000000000388
}

This information is current as of August 25, 2017

\author{
Updated Information \& \\ Services \\ Supplementary Material \\ References \\ Citations \\ Subspecialty Collections \\ Permissions \& Licensing \\ Reprints
}

including high resolution figures, can be found at:

http://nn.neurology.org/content/4/5/e388.full.html

Supplementary material can be found at:

http://nn.neurology.org/content/suppl/2017/08/25/4.5.e388.DC1

This article cites 10 articles, 0 of which you can access for free at: http://nn.neurology.org/content/4/5/e388.full.html\#\#ref-list-1

This article has been cited by 3 HighWire-hosted articles: http://nn.neurology.org/content/4/5/e388.full.html\#\#otherarticles

This article, along with others on similar topics, appears in the following collection(s):

Multiple sclerosis

http://nn.neurology.org//cgi/collection/multiple_sclerosis

Information about reproducing this article in parts (figures,tables) or in its entirety can be found online at:

http://nn.neurology.org/misc/about.xhtml\#permissions

Information about ordering reprints can be found online:

http://nn.neurology.org/misc/addir.xhtml\#reprintsus

Neurol Neuroimmunol Neuroinflamm is an official journal of the American Academy of Neurology.

Published since April 2014, it is an open-access, online-only, continuous publication journal. Copyright

Copyright $\odot 2017$ The Author(s). Published by Wolters Kluwer Health, Inc. on behalf of the American

Academy of Neurology.. All rights reserved. Online ISSN: 2332-7812.

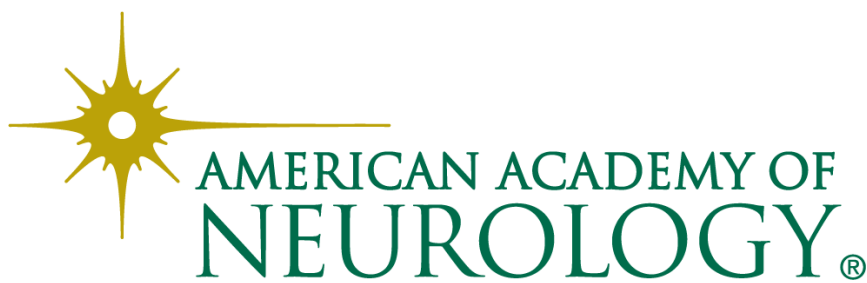

